\title{
Biblical Foundations of Short-term Missions (STMs) and Its Implications for Christian Higher Learning
}

\author{
Rosemary Wahu Mbogo \\ School of Education, Arts and Social Sciences, Africa International University, Kenya
}

Copyright $\subseteq 2019$ by authors, all rights reserved. Authors agree that this article remains permanently open access under the terms of the Creative Commons Attribution License 4.0 International License

\begin{abstract}
The practice of Short Term Missions (STM) has been on the rise for the last three decades. The trend in short term missions has been growing over time both locally and globally. However, there are questions as to whether STM is authentically biblical especially in comparison to Long Term Missions (LTM). Moreover, the academia has not engaged on the discussions and it also seems to be lagging behind in the use of the STM model to accomplish her vision and mission. There is therefore need to provide a clearer understanding of the phenomenon. In this paper, the author discusses the concept of Short Term Missions demonstrating its biblical foundations and the globalization effects of STM with a focus on Christian higher learning. Further, a model for STM is proposed for institutions of higher learning to adopt.
\end{abstract}

Keywords Short Term Mission, Higher Education, Globalization, Biblical Perspective

\section{Introduction}

There has been a lot of attention driven towards short term mission (STM) with Missiologists debating over the global effects of this phenomenon on general mission work [1]. The interest in carrying out Christian missionary work has bred a myriad of short term missions' activities and as recognized in Maximum Impact Short-Term Mission by Aeschliman and Sneed [2], "at least one million individuals are going out every year into short-term mission service" [p. 243]. However, while the phrase short term mission has been adopted globally in mission work, the term has not uniformly been defined by scholars creating a controversy in literature about STM. These controversial opinions have led to various sentiments for and against STM. In my opinion though, the disparity is due to varying definitions of the term. This paper therefore brings to focus the concept of short term mission discussing its usage in the biblical perspectives in relation to the mission as carried out today in our society.
There are many activities done under the umbrella of short-term missions that do not qualify to be called missions. So, what is STM? In my definition, it is the involvement of believers, both lay and clergy, in short term activities with an aim of proclaiming the gospel message through word and deed, including in a local context as hosts or other contexts (local, regional or global), as hosted (missionary). The main focus is not the length of involvement but the purpose of involvement. However, depending on the purpose, length of STM usually varies from a few days to a few weeks, months or a few years. According to Schwartz [3], short-term missions can be categorized into two based on the length of mission thus; 2-6 week short visits by individuals who are on 'working vacation' and 6months -3 years which are longer STMs often undertaken by professionals on sabbatical, volunteers and retirees who are willing to dedicate some time to the service.

It is important to understand the term from a biblical perspective for authenticating the use of the STM model in gospel outreach because "the mission of the church, including mission trips, is meant to be just that-to proclaim the good news of Jesus Christ, particularly, the forgiveness of sins. However, the mission of the church has been made into a social justice goal that seeks to help the forgotten, the needy, and the lowly, especially in places that "need our help" [4, p. 81].

Short Term Mission model has grown significantly in the last four decades.

Starting in the 1980s, short-term mission found itself in an analogous position vis-à-vis the academy. In post-war North America, STM grew from a relatively small number of participants barely noticeable among the established missionary community into a massive phenomenon involving upwards of two million people per year [5, p. 125]

\subsection{Effects of Globalization}

While short term missionary work has given an opportunity to many in experiencing life and ministry of a 
foreign culture, the effects that globalization has had on the same cannot be overlooked. Globalization, driven by people as posited by Blair [6] has both bad and good effects. Blair acknowledges the multidimensional nature of globalization cutting across all aspects of life including culture, religion, economy and politics among others. This paper however focuses on the religious aspects concerned with short term missions.

Through globalization, countries of the world have been able to make connections for various purposes. "Global connections of local congregations with congregations and ministries in different cultures have grown to include not just financial support and the sending of specialists, but direct, hands-on participation by increasing numbers of members-at-large" [7, p. 309]. Globalization as a force drives individuals of different religious back grounds together living and thriving together despite their places of origin [7]. However with the increasing rate of globalization individuals tend to lose identity feeling threatened in their religious environments due to the challenges brought about by globalization [6].

The astronomical growth indicates a need that is being met, either by the missionaries themselves, or the hosts, or both. However, activities of STM have mutated with time and range from volunteerism in community work, tourism to religious activities. STM is not social work or tourism. However, many short-term trips have been planned with the purpose of social action and touring the world, with little or no focus on the gospel message. The latter has yielded criticism, almost to the detriment of STM or to those who have participated in such in later self-reflections. (I will never forget listening to a lady who cried miserably for having been involved in short term missions and feeling that she had just been imposing her agenda to the people she thought she was ministering to. Unfortunately, she used her personal experience to disregard most STM activities and began a movement to do it better. Unfortunately, the "better option" thrives at criticizing others).

While self-reflection and mission assessment are important, self-criticism and despair can have risky results that must be prevented. I totally believe that at a particular time in our lives God allows us to have some limited information about his will for our lives. Provided we fully obey with an intention to accomplish God's will for our lives as per the provided information (of course with the expectation that we do our due diligence to understand the mission), God is glorified. If we learn things that would help us improve in the future, that is great; but we should not trash past experiences as useless. Conversely, we should not use our new knowledge to undermine what others are doing as they take baby-steps.

\subsection{Assessing Short Term Missions}

Objectivity in assessing STM is needed. Such objectivity can only be achieved if based on an understanding of biblical and theological basis for STM. According to Robinson [8],

Short-term mission (STM) has both its advocates and its nemeses in our postmodern context. In the course of reviewing hundreds of sources, I have come to the conclusion that the advocates often over-estimate the value of STM by allowing any group of people moving from one place to another to constitute "missions" regardless of what their purpose may be. On the other hand the missiological nemeses of STM have managed to pin nearly every problem on the mission field to a bad experience with a group of "ugly Americans" on a STM assignment. ${ }^{1}$ Both assessments are subjective in nature and are less than helpful in the task of completing the Great Commission. What is needed is an objectively grounded assessment based upon the phenomenon's biblical roots. If it can be established that there is biblical precedence for STM and that the approach is not a violation of theological orthodoxy / orthopraxy, then the missiological community should exert its gifts toward the end of discerning a strategic use for the approach. [1]

\section{Biblical Foundations for STM}

Despite the growing interest in short term missions, the subject has been disregarded over a long time with just a few missiologists and scholars drawing attention to the phenomenon [1]. Most scholars however according to Armstrong have expressed strong disapproval for the abominable mistakes made while undertaking short-term missions. Some have gone further to advocate for a call off on the mission work altogether while others glorify the practice as a welcome transition to twenty-first century missionary work. Following such mixed reactions it is important to draw a clear foundation for the short term mission work upon which the whole exercise can be based. In the following section therefore we consider the Old Testament and the New Testament foundations for Short Term Missions drawing biblical examples.

\subsection{Old Testament Foundations}

The practice of short term missions is founded in the bible with the Lord of all nations commanding churches to engage in evangelism across nations and cultures of the world. The involvement of churches and individuals in short term missions is therefore crucial to help "Declare His glory among the nations, and marvelous works among all peoples" (Psalm 96:3) [9].

There are various circumstances in the Old Testament that depict the practice of short term missions and are

1 Ralph Winter. "The Greatest Danger. The Re-Amateurization of Mission.” Missions Frontier Bulletin, March-April, 1996. 
therefore listed in this paper as follows:

- The origin of mission work begins with God when He finds man hiding in shame and guilt after the Fall.

- $\quad$ By His grace, he provided coverings for Adam and Eve and promised to use the seed of the woman to crush the heel of the Serpent.

- As a missionary God, He seeks to partner with us in accomplishing what he started in the beginning and which has been revealed through Jesus Christ, the one who came to destroy the works of the evil one. This marks a genesis of mission work.

- In the Old Testament, we also see Noah commissioned by God to proclaim repentance and to build an ark for those who would believe to be saved from the floods. In this case, Noah is called a missionary in his own context, for unidentified period of time.

- Later, Abraham is called out of his home to a country he did not know about, and never to return to his homeland. Through him, the nations of the world would be saved. He was therefore called for a lifetime mission, a Long-Term Mission (LTM).

- Later, for Sodom and Gomorrah, God sends the "three" strangers (angels) to save those who would believe and escape the imminent destruction of the city. In this STM model we get to see the place of intercession in saving people - the house of Lot was saved because of Abraham's intercession (Gen. 18).

- As the children of Abraham, and later Israel, settled to become a nation, they were expected to live by God's standards to teach foreigners living among them, through modeling the ways of God (Lev. 19; Num. 15). The Levitical system comprised of the tribe of Levi that was called to serve God through teaching of His word among the different tribes of their nation - a basis for LTM, so to say. As the nation progressed and began to interact with other nations, God raised prophets, some of who were sent to other nations. For example:

1. Jonah was sent to Nineveh

2. The prophet of Judah was sent to Israel

3. Obadiah was called to prophesy against Edom

4. Isaiah, Jeremiah, Amos etc. prophesied on many nations - though not clear whether they physically went there or not, the treatment of the Babylonians on Jeremiah suggests some familiarity with the prophet and the content of his prophecy

5. Hezekiah's emissaries to teach - the Levites were sent in groups to teach the word of God to the Israelites

6. Nehemiah's mission - as the King's cupbearer, Nehemiah responded to the need to act on the broken wall of Jerusalem. His mission that lasted a couple of months (52 days constructing the wall), involved not only the physical building but also social, economic and spiritual reconstruction.

\subsection{New Testament Foundations}

By the coming of Jesus, the Jewish nation had been through exile and the remnants had returned; the nation was under the rulership of foreigners - the Romans. In the context of suffering and oppression, Jesus comes to bring the reign of God, not through political systems, but through proclamation of the good news of the kingdom of God. A pertinent foundation in church missionary is demonstrated through Jesus' significant representations of God's kingdom and is applicable for the short mission work in the world today. While secularists in the contemporary society would not express approval for the church with the custody of such a fundamental burden of responsibility, Smith [10] acknowledges that in the period we live in today, a structure of sustainable values for mission practices are crucial. Following are some of the examples quoted in the New Testament depicting mission works.

1. Jesus' mission - Jesus came to earth for 33 years of his earthly life - in a way a long-term mission (LTM), but on day to day implementation of his mission, He moved from place to place in short term missions (STM). He traversed Judea, Galilee and Samaria.

2. Jesus' disciples - They were sent two by two, into villages and homes on short term mission (Lk. 10)

3. Peter and the elders - At Samaria, they went to see how believers were doing after the preaching of Philip (Acts 8)

4. Paul's missionary journeys - His call was LTM, but his implementation called for involvement on STM and even medium-term missions (MTM).

5. Paul's coworkers - Barnabas accompanied Paul in some STM's, Luke accompanied Paul as well, Timothy was left in Ephesus on a STM etc.

There are many examples of STM and regardless of our vocations; God has used STMs to accomplish His purposes. It is important therefore as coworkers with God to embrace the place of short-term mission in our lives and to allow God to accomplish his eternal purposes through us.

\section{Models of STM}

1. Group-based - group STMs were common in the early church, perhaps due to the approach Jesus used on the disciples, sending them two by two. Such team works brings along synergies that make the work effective. They also provide opportunities for accountability.

Most of the missionaries that have come to proclaim 'By Grace' have been mostly in groups. The groups have been consistently planned by a head of a non-profit, a mission's 
director at a church or a faculty member at a university. Group based models tend to be:

a. Proclamation-based - the basis of all STM is proclamation and discipleship. However, the point of connection can be work place (Jesus and the call of disciples from fishing, tax collecting, etc.); Outdoors (Nathaniel and the Samaritan woman). Hence, community development models, without proclamation and discipleship do not qualify to be STM on their own.

b. Community Development-based - some contexts demand community-based outreach. In such cases where social action activities are established first, they should be for providing connections needed for proclamation and discipleship. The effectiveness of all STMs therefore should be assessed based on discipleship indicators and not the number of projects (Matt. 9:35).

c. Holistic - Proclamation and discipleship activities that do not have practical social-economic interventions are not enough. Jesus combined both; He preached both in Word and Deed. Integration is the call that Jesus gives us. This is the model I have seen as most effective in Africa (Acts 10:38). A short-term mission geared to meeting holistic needs is sometimes more complicated to plan but by far is the most useful that I have witnessed. The Foundation for Peace (FFP) has been implementing this model with great success. The story began when my husband, whose main mission with African Enterprise (International) is evangelism (in word and deed), met with Dr. Ken Culver who had done medical missions in the Dominican Republic and Haiti for many years. They both felt an integrated mission will be desirable. In 2007, the first integrated mission was conducted in Kenya. The host was African enterprise. As is the motto of FFP to create a landmark in every mission, the group had raised $\$ 10,000$ and wanted it to build a church or another deserving project. By Grace Children's home had a stalled project and the group was excited to be part of the project. For four days, the US group partnered with the host (By Grace children, staff, AE partners and a few skilled contractors) to construct the walls. They then left the experts to begin working on the technical parts of the roof as they embarked on another aspect of the ministry - the medical camp. The medical camp took three days. It was organized in a way that at the waiting bay, there were various people offering prayers, counseling and other care provision to those who came for treatment. Later we realized that some of those who came sick did not have adequate food to guarantee the effectiveness of the medication they underwent. Hence, another room was set up to provide some relief food to those who came. Within the weekend, over 200 families come to the camp. Some have been referred for further treatment in hospitals and those with more complicated situations have had support raised to assist them receive specialized treatment. As the doctors, nurses and other medical attendants are doing that work, another group is involved in proclamation - through open air meetings. A group of teachers is doing teacher and training etc. Then one day is spent visiting HIV/AIDs patients in the homes by everyone, and two Sundays are spent in the church with everyone scheduled to share their experiences. Of course, everyday there are debriefing activities, devotions, entertainment and host-sent interactions that are built within daily activities to facilitate information processing and decision making. After the 10 days of working with the host, the missionaries choose whether to go on safari or not. In this model, the scenario that has been described as "raising American money and spending it on American's needs" is avoided. Local businesses are promoted instead, relationships are built during constructive conversations while working together; all participants: male and female, young and old, and local and foreigner find common ground for long term conversations. Even the foreigner learns from the local. The exchange is mutually transformative.

2. Individual-based - the examples of Apollos (Acts 18) and Philip (Acts 8) stand out in the New Testament. They went preaching and teaching the good news. In some instances, after groups have come on STM, individuals have decided to return as they felt the need to continue with the mission work. This is primarily where the individual finds a skill/gift match to meet a need that requires more time. Some have stayed for a couple of weeks up to a year. In very few instances, we have had requests to host an individual who has not come through STM. Such are usually referrals or networks gained in conferences and other contexts. In many cases, these happen to do it as part:

a. College credits based - some individuals on internships are motivated by the need to earn credits, either as an internship or electives.

b. Gap year based - some graduates, especially high school, tend to prefer spending a gap year before joining college doing mission work. Some college graduates also take a gap year, before work and family responsibilities, to participate in short term mission work.

c. Transitions based - if a few cases, some life transitions have often opened minds to consider short term missions as they think of next steps in life. While for some it is career change, for others it is unfortunately a major loss - such as bereavement and divorce, among others. 
It is important to mention that since groups are made up of individuals, the above are also characteristic of individuals within group-based models. Individuals are usually open to try different activities as maybe needed by the host, though at times they can end up creating their own agenda apart from the host's.

In a study conducted by Priest [11], STM movement leaders have continuously asserted that STMs add to the pool of Christians willing to serve as career missionaries while increasing their financial giving in support of career missionaries [p. 435]. More so, studies have indicated that "involvement in STMs increases openness to serving as a career missionary" but to prove the increase in giving is more difficult since most of the missionaries on mission trips are low income earners [p. 436]. In essence, the resultant benefits are only based on how long the openness to becoming a career missionary remains an option in the minds of STM participants.

\subsection{Outcomes of Short Terms Missions - Lessons from Jesus}

Repentancel salvation/ healing/ forgiveness/ e.g. African Enterprise/ local and international missionaries. The hallmark of any Christian mission should be repentance and forgiveness of sin as people become reconciled with God through Christ and with one another. This is the major difference between short-term missions done by Christians and some social action activities done by any non-Christian philanthropist. In addition to salvation, healing of body, soul and mind need to be outcomes of short-term missions. Foundation for peace has been very open to suggestions that we make and included an aspect of proclamation in their outreach. Through our partnerships, those who come share their testimonies or messages and those hosting do the same during various activities of the short term mission program.

Training/ acquisition of knowledge, skills, values, attitudes (education) - training is always an area of need in any ministry. Even Jesus had to train the twelve and the seventy disciples. Through training, knowledge is imparted, skills are multiplied, and values and attitudes are "caught" and cultivated. Short term missions therefore need to include an element of training hosts according to areas of need. It has been interesting to participate in short term missions where our basic education providers (both trained and untrained teachers) have been given in service training during a short-term mission. For example, teacher training has been handled through the Foundation for Peace teacher teams. Teachers have also been trained in psychological counseling areas through a group of graduate students at Asuza Pacific University.

Development/ Relief - Caring for the poor was a major part of Jesus' ministry (part of the collections for the bag under the care of Judas). Activities such as caring for widows (Jesus to John on the care of the mother), advocacy (for the woman caught in the act), cross cultural engagement (Jesus and the woman at the well) and feeding the poor (feeding the five thousand), among others indicate the need to engage with relief work. The main challenge is where outcomes are dependency and where people are made professional beggars. All relief work needs to be done strategically to allow people to grow in the dependency on God. Usually, short term mission activities are done because of felt and perceive needs, always ranging from spiritual, social-economic and psychological needs. It is therefore important for short term mission to include this part. My experience is that, when well-coordinated, those physical activities make perfect opportunities for cross-cultural interactions. Again, through FFP buildings have been constructed such as schools and churches, basketball courts built, and medical clinics supplied with medication etc. These facilities have been very helpful for the local ministries. They have also helped in national development and contribute to the overall welfare of communities.

Dignity to the host, vulnerability to the hosted and exposure for both - when done with mission in focus, STM can provide opportunity for boosting the morale of the host. Regardless of social strata, a host is empowered to offer a service needed by missionaries. It is an opportunity that helps the host feel dignified in addition to providing opportunity for learning in logistical planning and service provision. For the missionaries it is an experience of great vulnerability as life is greatly dependent on the host. This provides a lot of opportunity for self-reflection. For both the host and the missionary, a great door of exposure across culture which enhances creativity. New approaches to missions can be achieved through contextualization, e.g. Paul in Athens after having some experiential knowledge of the culture and figuring out an entry point.

Replication and expansion of STM - whenever short term missions are accomplished properly, people tend to wish for more and replication becomes a natural response. People also talk about their experiences with their social networks and from the ripple effect of sharing, more people participate. The result has been the ability to access many listeners. Even small churches or ministries have had opportunity to send missionaries or to host missionaries with the result of being empowered in some ways. Since LTMs had established their mission stations, only a limited number would benefit from cross-cultural interaction. In Kenya, we have churches now sending missionaries through STMs both locally, regionally, continentally and even internationally. e. g. AE - to Uganda, Kenya, Ghana, etc.; Churches like Nairobi Chapel, Christ is the Answer Ministries among others.

Overall, I have seen lives that have been saved, communities transformed, buildings contracted and water provided among other services through STM. 


\section{Challenges of STM}

\section{For the Missionary}

1. Generalizations - due to the limited time accorded to many STMs, it is possible for missioners to assume they have learnt how life is lived in a new culture. Many times, people may have great experiences and have a utopian perspective of individuals, groups or entire host. Sometimes the experience may not be as expected, and missioners may leave with feelings of being short changed and a dislike towards STM or even missions in general. STM need to provide opportunities for interactions for clarifications and feedback between the host and hosted. Hence, STM should be relational. (e.g. Paul's coworkers).

2. Touristic tendencies - due to the many opportunities to go for STM, many believers forget the main purpose of a mission. Their main desire is to tour the world and they take every opportunity that comes to go to the next country. Hence, STM must intentionally aim to be related and model. It is probably best to have relationships with one host for several years, with a purpose to accomplish something, before going to the next engagement. Hence, STM should be incarnational. (John 1:14 - the word became flesh and made his dwelling among us)

3. Superficiality - due to the limited time to cultivate relationships and engage in long term projects, it is possible to have superficial relationships, and superficial projects that are not likely to bring about significant transformation. Listening to the needs of the host without patronizing is key. Hence, STM needs to be strategic. e.g. Paul and appointing of elders.

\section{For the Host}

1. Generalizations - just like it happens for the visiting, it is possible for host to have generalizations about the culture of the visitors. Some of this rage from assuming the high energy and excitement level as indicator of a great relationship or offer of small gifts as willingness to solve financial problems.

2. Unrealistic expectations - the west has always been known to comprise developed countries and people coming on STM are perceived to be wealthy. It is reality that there is a great economic divide between western teams and local hosting teams. Most hosting teams expect that STM will lead to less financial issues in their ministries. It is therefore possible for many to share their personal or institutional financial needs with mission teams.

3. Passivity - there is so much that happens in a STM inform of activities and information sharing. Interactions usually lead the visiting team to understand how they can be helpful. Due to the economic realities that surprise the missionaries, the spontaneous desire to what to help and alleviate situations of human depravation is natural and human. However, the host may not have premeditated on what can be done. Sometimes, due to language barriers - and here I mean, not the proficiency, but the mental processing capability that is dependent on whether the language being used in foreign or mother tongue. Additionally, in many African contexts, saying no to the suggestions of a good visitor is seen as rude. Usually, hosts end up accepting suggestions of the visitors passively.

Community Suspicion - participation in STM usually brings diverse cultures and races together. Usually, communities in Africa will always know when there are guests. Since these guests are usually foreigners, communities conclude that the hosting institution is receiving much money. Unfortunately, if the local host is in need of local funds, this is not easily given due to the wrong perceptions. On the contrary, such communities expect the institution to "share with them what the guests have given".

\section{The Place of STM in Christian Higher Education}

Although STMs have been going on for a while, little has happened among Christian institutions of higher learning. This is enigmatic given that STMs are primarily comprised of Christian college students as the highest number of participants, globally and locally. Due to immense numbers of lay people leading STM teams, there have been mistakes done by STM teams out of ignorance. Since institutions of higher learning are meant to be centers of critical thinking and reflection, research and innovation to help society, Christian universities have potential to provide for theory and praxis gaps in STMs.

Missionary teams can therefore be hosted by university students, faculty and staff, in partnership in local ministries. Through such, various short term mission activities can be conducted both within the universities and its environs. This is because Christians joining Christian universities have increasingly been nominal. Many do not even know basic tenets of their faith and some have not personalized the faith of their parents of sponsors. Christian universities are also in dire need of internal short term mission activities including evangelism, discipleship, construction, medical outreach, and various charity works, due to various needs presented primarily by their students.

Moreover, public and non-religious universities have generally tended to be more secularized and unevangelical. As centers of learning, Christian universities can reach out to secular ones and their own environment with the gospel. Additionally, there is a great opportunity for universities to partner with short term mission groups and reach out to 
their communities both in evangelism, discipleship, building, training and other activities. What can we do in this area? I believe that Christian universities all over the world could partner through STMs, they could reach their secularized institutions both in Africa, in the US and the rest of the world with the gospel of Christ, both in word and deed.

Christian institutions of higher learning can also provide leadership in pre-mission, on-mission and post mission training. This training can either be for non-credit or can incorporate an academic component allowing students to earn credit.

Finally, Christian universities can be centers for research in monitoring and evaluating the effectiveness or impact of STM. Continuous assessment would provide necessary feedback for STM organizers to improve. Currently, reflections on the impact of STM are at personal reflection level and decisions are being made based on subjective opinions of individuals or groups. Research is needed to help guide in decision making and in improving STM.

\section{Implications to Ministry}

Short term missions have a basis in scripture and therefore assessment of STMs should not begin by asking whether the model is right or wrong. The model is founded in scripture. The question should therefore be what is being done right and how can the wrongs be corrected. Even with the latter, any criticism should bear in mind that many short-term missionaries and believers have a sincere purpose to please God.

Over the last twenty years, churches across the country have seen a significant growth in mission trip experiences. People of all ages have said "yes" to travel to destinations that are often not normal vacation locations. Why? Some people want to see the world. Some people want to go on a mission trip to check it off the bucket list. But, most of them are looking for a way to connect with God, connect with members of their church community, and connect with a culture that is so radically different from anything they have ever experienced [12, p. 80].

\section{REFERENCES}

[1] Armstrong, S. A. (2006). The role of short-term missions in a long-term mission strategy. World Mission MAC Region Church of the Nazarene.

[2] Aeschliman, P. \& Sneed, W. (2003). Maximum impact short-term mission. The God-commanded repetitive deployment of swift, temporary non-professional missionaries. Minneapolis: STEM Press.

[3] Schwartz, G. (2003). Two Awesome Problems: How Short-Term Missions Can Go Wrong. International Journal of Frontier Missions, 20(4), 27-34.

[4] de Castillo, A. O., \& Castillo, H. (2010). Short-Term Mission Experiences. Word \&World, 37(1), 81-83.

[5] Priest, R. \& Howell, I. B. M. (2010). Introduction: Theme Issue on Short-Term Missions. Missiology: An International Review, 41(2) 124-129.

[6] Blair, T. (2009). 'Faith and globalization', in Blair Foundation Lectures, voice recording, Tony Faith Foundation, viewed 15 May 2015, from $\mathrm{http}$ //tonyblairfaithfoundation. org/projects/supporting-lea ders/supporting-leaders-teaching-resources

[7] Barber, R. (2015). Host-directed short-term missions: Interviews with Japanese liaisons. Missiology: $A n$ International Review, 43(3), 309-323.

[8] Robinson, G. (2010). Biblical Foundations for Short-Term Missions. In "Featured Articles" section www.globalmissiology.org.

[9] Borthwick, P. (2001). Reaching the world short-term. Moody Magazine. Retrieved from http://www.moodymaga zine.com/articles.php?action=view_article\&id $=153$.

[10] Smith, J.K.A. (2014). How (not) to be secular: Reading Charles Taylor. New York, NY: Eerdmans Publishing Company.

[11] Priest, R. J. (2006, October). Introduction to Theme Issue on Short-Term Missions. Missiology, XXXIV (4), 431-450.

[12] Elton, E. (2017). Short-Term Mission Experiences. Word \& World, 37(1), 80-82. 